\title{
A systematic review and meta-analysis of nut consumption and incident risk of CVD and all-cause mortality
}

\author{
Alexandra J. Mayhew ${ }^{1}$, Russell J. de Souza ${ }^{1}$, David Meyre ${ }^{1,2}$, Sonia S. Anand ${ }^{1,3,4}$ and Andrew Mente ${ }^{1,3 *}$ \\ ${ }^{1}$ Department of Clinical Epidemiology and Biostatistics, McMaster University, Hamilton, ON, Canada, L8N $3 Z 5$ \\ ${ }^{2}$ Department of Pathology and Molecular Medicine, McMaster University, Hamilton, ON, Canada, L8N 3Z5 \\ ${ }^{3}$ Population Health Research Institute, Hamilton Health Sciences, McMaster University, Hamilton, ON, Canada, L8L 2X2 \\ ${ }^{4}$ Department of Medicine, McMaster University, Hamilton, ON, Canada, L8S 4 K1
}

(Submitted 14 April 2015 - Final revision received 30 September 2015 - Accepted 1 October 2015 - First published online 9 November 2015)

\section{Abstract}

Dietary patterns containing nuts are associated with a lower risk of CVD mortality, and increased nut consumption has been shown to have beneficial effects on CVD risk factors including serum lipid levels. Recent studies have reported on the relationship between nut intake and CVD outcomes and mortality. Our objective was to systematically review the literature and quantify associations between nut consumption and CVD outcomes and all-cause mortality. Five electronic databases (through July 2015), previous reviews and bibliographies of qualifying articles were searched. In the twenty included prospective cohort studies ( $n 467389$ ), nut consumption was significantly associated with a lower risk of all-cause mortality (ten studies; risk ratio (RR) $0.81 ; 95 \%$ CI $0.77,0.85$ for highest $v$. lowest quantile of intake, $P_{\text {het }}=0.04, I^{2}=43 \%$ ), CVD mortality (five studies; RR 0.73; $95 \%$ CI $0.68,0.78 ; P_{\text {het }}=0.31, I^{2}=16 \%$ ), all CHD (three studies; RR 0.66; $95 \%$ CI $0 \cdot 48,0.91 ; P_{\text {het }}=0 \cdot 0002, I^{2}=88 \%$ ) and CHD mortality (seven studies; RR $0.70 ; 95 \% \mathrm{CI} 0.64,0.76 ; P_{\text {het }}=0.65, I^{2}=0 \%$ ), as well as a statistically non-significant reduction in the risk of nonfatal CHD (three studies; RR $0.71 ; 95 \%$ CI $0.49,1.03 ; P_{\text {het }}=0.03, I^{2}=72 \%$ ) and stroke mortality (three studies; RR $0.83 ; 95 \%$ CI $0.69,1.00$; $\left.P_{\text {het }}=0 \cdot 54, I^{2}=0 \%\right)$. No evidence of association was found for total stroke (two studies; RR $1 \cdot 05 ; 95 \%$ CI $0 \cdot 69,1 \cdot 61 ; P_{\text {het }}=0 \cdot 04, I^{2}=77 \%$ ). Data on total CVD and sudden cardiac death were available from one cohort study, and they were significantly inversely associated with nut consumption. In conclusion, we found that higher nut consumption is associated with a lower risk of all-cause mortality, total CVD, CVD mortality, total CHD, CHD mortality and sudden cardiac death.

Key words: Nuts: Mortality: CVD: CHD

CVD is the leading cause of death globally, accounting for $30 \%$ of all deaths worldwide ${ }^{(1)}$. The CVD burden is projected to increase in the next two decades. Although pharmacological treatments (e.g. statins) have contributed significantly to reduced CVD morbidity and mortality globally ${ }^{(2)}$, recent reviews of the evidence suggest that statins may increase the risk of type 2 diabetes $^{(3)}$, as well as be medically contraindicated for some persons. Thus, lifestyle modification, including healthy eating, remains a cornerstone of CVD prevention.

In recent years, a substantial amount of data have shown that fat quality is associated with CVD surrogate outcomes and events ${ }^{(4-6)}$. A readily available source of unsaturated fat is nuts, which include tree nuts (e.g. almonds, hazelnuts, walnuts and pistachios) and peanuts (technically a legume but with a similar nutrient composition to tree nuts) ${ }^{(7)}$. Randomised controlled trials (RCT) have shown that dietary patterns containing nuts such as the 'Mediterranean diet' reduce CVD mortality in healthy ${ }^{(8)}$ and high-risk populations ${ }^{(9)}$. There are also many clinical trials investigating the effect of nuts on risk factors of CVD such as serum lipid levels and lipoproteins ${ }^{(10)}$. However, to date, there is a paucity of data from clinical trials assessing the independent impact of nut consumption on CVD events. Meanwhile in recent years, additional data from prospective cohort studies with a substantial number of mortality outcomes including CVD and individual events such as myocardial infarction and stroke have been published $^{(11-14)}$. Since January 2013, there have been six metaanalyses related to CVD and nut consumption ${ }^{(15-20)}$. However, the most recently updated literature search was conducted in June 2014 and limited outcomes to all-cause mortality, CVD mortality and cancer mortality ${ }^{(15)}$. Since that time, three large prospective cohort studies of nut consumption and CVD outcomes with initial or expanded analyses have been published ${ }^{(21-23)}$. Our study also offers the advantage of being specific to nuts, whereas other previous meta-analyses have included studies that group nut consumption with other food groups including seeds or fruit, which may introduce imprecision into the results.

Abbreviations: GRADE, Grading of Recommendations Assessment, Development, and Evaluation; NOS, Newcastle-Ottawa Scale; RR, risk ratio.

* Corresponding author: A. Mente, email andrew.mente@phri.ca 
In this study, we systematically reviewed the updated literature on nut intake and CVD events and investigated associations with additional cardiovascular outcomes such as stroke mortality and sudden cardiac death. Further, we used GRADE (Grading of Recommendations Assessment, Development, and Evaluation), to assess the quality of the evidence for each outcome of interest and to help facilitate incorporation of our findings into nutrition policy and guidelines development.

\section{Methods}

This review was conducted in accordance with the Metaanalysis Of Observational Studies in Epidemiology (MOOSE) guidelines (online Supplementary Appendix S1) ${ }^{(24)}$. Ethics approval was not required for this research.

\section{Search strategy and study selection}

An electronic search strategy was developed to identify observational human studies (prospective cohort, retrospective, nested case-control or case-cohort design) and randomised trials investigating nut consumption and mortality and CVD outcomes. We searched MEDLINE (1946 through 8 July 2015); EMBASE (1974 through 8 July 2015); Cochrane Central Registry of Controlled Trials (1996 through 8 July 2015); Evidence Based Medicine Reviews Health Technology Assessment (1996 through 8 July 2015); and Evidence Based Medicine NHS Economic Evaluation Database (1996 through 8 July 2015). The bibliographies of retrieved articles were reviewed for additional studies. Studies were limited to original English language articles that included the terms mortality, CVD, myocardial infarction, CHD, stroke, brain ischaemia, cerebrovascular accident, sudden cardiac death, CHD or CVD mortality as the outcomes of interest and nuts, walnut, almond, pecan, macadamia, hazelnut, peanut, pistachio or peanut butter as the exposure variables being explored. The full search strategy is presented in online Supplementary Appendix S2. One reviewer (A. J. M.) assessed titles and abstracts of all studies identified through electronic searches. Potentially eligible studies were reviewed independently by a second reviewer (R. J. d. S.) with discrepancies resolved by discussion. A third author (A. M.) was consulted to reach consensus when necessary.

\section{Data extraction}

Two authors (A. J. M. and R. J. d. S.) independently extracted details of the study design, country of conduct, assessment of exposures and outcomes, participant characteristics and statistical analyses including degree of adjustment for potential confounders using pre-tested instruments. Discrepancies were resolved by discussion. In cases in which two or more manuscripts provided the same estimates of association from the same cohort, we chose the one with the longest follow-up time. For each study, the most-adjusted multivariable risk ratio (RR) and corresponding $95 \%$ CI for each outcome were extracted, including data on different types of nuts when provided. For studies with more than one multivariable adjusted model, we selected the most-adjusted model that adjusted for potential confounders including other dietary factors associated with nut consumption (such as fruit and vegetables or alcohol) but without the inclusion of variables on the putative causal pathway (e.g. blood cholesterol and blood pressure), where possible.

\section{Study risk of bias}

The Newcastle-Ottawa Scale (NOS) ${ }^{(25)}$ was used to assess the risk of bias of the included studies on the basis of selection of study groups, comparability of groups and ascertainment of the exposure or outcome of interest. The following elements were adapted for nutritional studies. Ascertainment of exposure: one star was given if a validated instrument (e.g. semi-quantitative FFQ) was used; however, as there is no accepted 'gold' standard of dietary measurement, one star was given if other instruments were used (e.g. multiple 24-h dietary recall or 7-d food records), and data were provided on (i) completion rate $(\geq 90 \%)$ or (ii) information on reliability from repeat administration, or it was explicitly stated that (iii) participants trained to complete records, or (iv) ambiguous or incomplete records were subsequently clarified. Comparability: each study began with two stars for 'comparability' and lost one star for each one of these five variables that was not controlled or matched for age, smoking, total energy and family history. For length of follow-up for outcome ascertainment, one star was given for follow-up of at least 5 years, chosen because a previous systematic review of $>200$ cohort studies relating dietary factors to CHD risk found that approximately $80 \%$ had a follow-up of $\geq 5$ years.

\section{Grading of Recommendations Assessment, Development and Evaluation}

The GRADE approach was used to assess the confidence in the effect estimates derived from the body of evidence (quality of evidence) by outcome and to produce evidence profiles ${ }^{(26-28)}$. Evidence summaries and GRADE assessments were discussed and reviewed by all investigators. Confidence in the estimate of each association was categorised into four levels, from very low ( $\oplus \bigcirc \bigcirc \bigcirc)$ to high $(\oplus \oplus \oplus \oplus)$. Outcomes were downgraded for inconsistency if the $I^{2}$ value for the summary relative risk estimate was $>50 \%$. If nut consumption was estimated using a non-validated method or if the outcome was self-reported, the outcome was downgraded for indirectness. To determine the presence of imprecision, we first considered the optimal information size (the number of cases included in the review compared with the number required by a conventional sample size calculation for a single adequately powered trial. On the basis of a $5 \%$ event rate in the control group and a $25 \%$ relative risk reduction, we calculated the optional information size to be 400 cases ${ }^{(29)}$. If the optimal information size criterion was not met, the evidence was downgraded for imprecision. The outcome was also downgraded for imprecision if the optimal information size criterion was met but the $95 \% \mathrm{CI}$ included $1 \cdot 00^{(30)}$.

\section{Statistical analysis}

The principal effect measures were adjusted RR between extreme levels of intake (highest $v$. lowest quantile) for prospective studies 
and the OR for retrospective studies. The principal effect measures were the RR between extreme levels of intake (highest $v$. lowest quantile). In cases in which at least two studies provided combinable data, a DerSimonian and Laird's random effects meta-analysis was performed, which yields conservative CI around the relative risks in the presence of heterogeneity ${ }^{(31)}$.

Heterogeneity was detected using Cochran's $Q$ test (significant at $P<0 \cdot 10$ ) and quantified using the $I^{2}$ statistic (ranging from 0 to $100 \%$ ), which informed the rating of the GRADE confidence in the estimates. Subgroup analyses were conducted to explore heterogeneity by sex (women, men, both sexes), geographic location and type of nut. Sensitivity analyses were conducted by removing studies with NOS scores $<7$ and re-calculating the pooled effect for each outcome. Outcomes that are potentially sensitive to quality include all-cause mortality and CHD mortality.

Dose-response meta-analyses were conducted using the method reported by Greenland \& Longnecker $^{(32)}$ and Orsini et $a{ }^{(33)}$. Study-specific slopes based on the results across quantiles of nut consumption were calculated using generalised least squares for trend estimation. The study-specific estimates were then combined using the restricted maximum likelihood method. The fully adjusted RR, 95\% CI, dose and number of cases and person-years were extracted for each study and outcome. The amount of nuts consumed was converted to servings per week (serving size of $28 \mathrm{~g}$ or 1 ounce) using the median or mean intake level for each quantile. Summary estimates for the slope of the association between nut intake and outcomes were computed for an increment of 4-weekly servings, which is consistent with the Dietary Approach to Stop Hypertension (DASH) eating plan ${ }^{(34)}$. For the highest dose category, the servings per week were estimated as the minimum for that quantile plus one half of the median/mean of the previous quantile to minimise potential for underestimation.

Publication bias was investigated by visual inspection of funnel plots and quantitatively assessed using Egger's and Begg's tests where a $P$ value $<0 \cdot 10$ was considered evidence of small study effects ${ }^{(35,36)}$. The trim and fill method was used to estimate the number of potentially missing studies in the meta-analyses and the effect these studies may have had on the outcome ${ }^{(37)}$.

We used commercially available statistical software, Review Manager ${ }^{(38)}$, to conduct the meta-analysis and Stata, version $14^{(39)}$ to conduct dose-response analyses and the assessment of publication bias.

\section{Results}

\section{Literature flow}

Of the 1490 potentially eligible articles that were identified, seventy-five remained after screening the titles and abstracts for applicability and twenty-six remained after full-text review. From these articles, twenty prospective cohort studies, which contributed at least one data point to the quantitative synthesis, were identified (Fig. 1). One case-control study was identified, which is discussed individually. No relevant RCT were found. Fig. 2 provides the pooled multivariable risk estimates for all outcomes.

Table 1 summarises the characteristics and results of the twenty prospective cohort studies (NOS scores in online
Supplementary Appendix S3). The articles were based on data from twelve different cohorts, seven of which are from the USA (Nurses' Health Study ${ }^{(13,40-43)}$, Physician's Health Study ${ }^{(11,13,40,44)}$, California Seventh-Day Adventist Study ${ }^{(14,45,46)}$, Iowa Women's Health Study ${ }^{(47)}$, Women's Health Initiative ${ }^{(48,49)}$, Atherosclerosis Risk in Communities Study ${ }^{(50)}$, Southern Community Cohort Study ${ }^{(21)}$, PREDIMED study and the Seguimiento University of Navarra (SUN) Project in Spain ${ }^{51,52)}$, Netherlands Cohort Study ${ }^{(53)}$, European Prospective Investigation into Cancer and Nutrition (EPIC) study in Germany ${ }^{(23)}$ and a sample of community dwelling people in the UK) ${ }^{(54)}$. Two RCT (Women's Health Initiative and PREDIMED) ${ }^{(48,51)}$ provided prospective associations according to reported nut consumption independent of randomisation assignment, and thus they were included as cohort studies. In total, 467389 participants were included in the analysis with a median follow-up time of 11.8 years (range, 4.6-30 years), a mean age of 60.4 years and $68.0 \%$ of participants being women. All studies used FFQ to assess nut consumption. The GRADE estimates of the quality of evidence are summarised in online Supplementary Appendix S4.

\section{Prospective cohort studies}

All-cause mortality. Ten prospective studies examined the association between dietary nut consumption and mortality from any cause $\mathrm{e}^{(21,40,45-48,51-54)}$. The summary multivariable RR for a meta-analysis of these ten studies with fifteen subgroups involving 277432 participants (182 272 women) with 49232 events over 4.6-30 years of follow-up was $0 \cdot 81$ (95\% CI $0.77,0.85 ; \quad P_{\text {het }}=0.04, \quad I^{2}=43 \%$ ) (least adjusted RR $0.78 ; 95 \%$ CI $0.73,0.82)$. The effect was similar in studies conducted exclusively in women $(0.84 ; 95 \%$ CI $0.81,0.88$; $\left.P_{\text {het }}=0 \cdot 40, I^{2}=3 \%\right)$ and in studies conducted exclusively in men (0.78; $95 \%$ CI 0.69, 0.88; $P_{\text {het }}=0.02, I^{2}=67 \%$ ) (Fig. 3). After removal of studies that scored $<7$ on the NOS, six studies with ten subgroups remained ref, $^{(21,46,51-53)}$ and provided a relative risk estimate of 0.79 (95\% CI $0.74,0.84 ; P_{\text {het }}=0.02$, $\left.I^{2}=56 \%\right)$. The GRADE estimate for quality of evidence was moderate $(\oplus \oplus \oplus \oplus \mathrm{)})$.

Total CVD. One study ${ }^{(41)}$ involving 6309 women with diabetes accrued 634 CVD events during the 8.7-year follow-up and showed a relative risk of 0.56 (95\% CI $0 \cdot 36,0 \cdot 88)$ (least adjusted RR $0 \cdot 43 ; 95 \%$ CI $0 \cdot 30,0 \cdot 61)$. The GRADE estimate for the quality of evidence was moderate $(\oplus \oplus \oplus \mathrm{)})$. The study was at a low risk for bias with a NOS score of 9 .

CVD mortality. In a meta-analysis of five prospective cohort studies $^{(21,22,40,47,51)}$ with seven subgroups involving 243795 participants experiencing 13726 events after 4.8-30 years of follow-up, the summary multivariable RR was 0.73 (95\% CI 0.68 , $0.78 ; P_{\text {het }}=0.31, I^{2}=16 \%$ ) (least adjusted RR 0.73; 95\% CI 0.73 , $0 \cdot 80$ ). When analysed separately, women and men had a similar risk estimate $(0.76 ; 95 \%$ CI $0.66,0.88 v$. 0.74; $95 \%$ CI 0.64, $0 \cdot 83$, respectively; $\left.P_{\text {het }}=0 \cdot 61, I^{2}=0 \%\right)$. Three studies ${ }^{(21,22,51)}$ in both men and women provided a relative risk estimate of $0.72\left(95 \%\right.$ CI $\left.0.64,0.81 ; P_{\text {het }}=0.13, I^{2}=47 \%\right)$ (Fig. 4). 


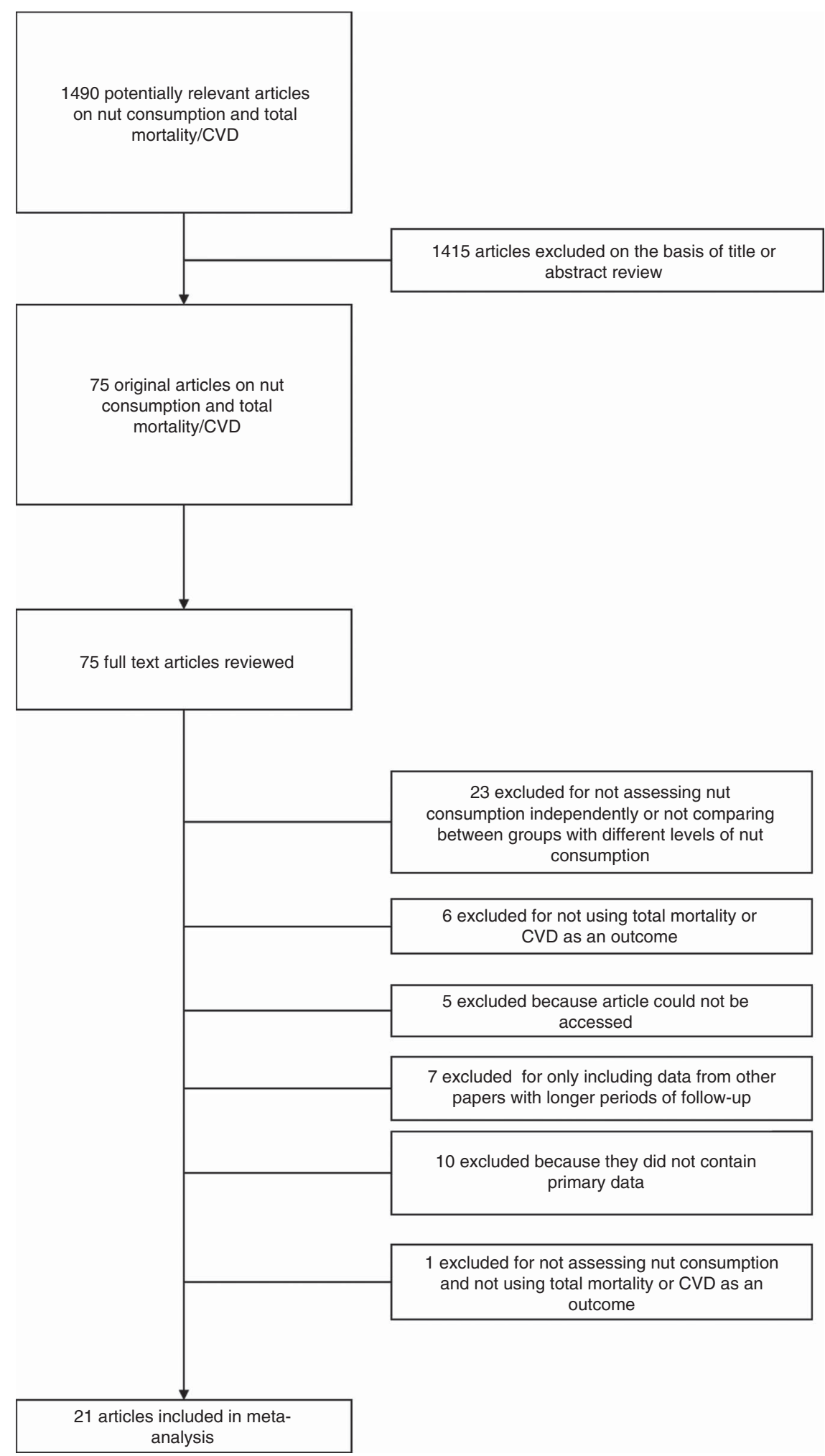

Fig. 1. Flow diagram of systematic literature search.

Removing the single study with a NOS below 7 does not materially alter the estimated relative risk $\left(0 \cdot 74 ; 95 \% \mathrm{CI} 0 \cdot 69,0 \cdot 79 ; P_{\text {het }}=0 \cdot 17\right.$, $\left.I^{2}=21 \%\right)$. The GRADE estimate for quality of evidence was low $(\oplus \oplus \circ)$ ).
Total CHD. For total CHD, the summary multivariable RR for nut consumption in three studies ${ }^{(42,50,55)}$ (three subgroups), including 123971 participants (87869 women) followed up for 6-26 years, accruing a combined 4757 events, was 0.66 (95\% CI 
Fig. 2. Summary meta-analysis of the association between nut consumption and all-cause mortality and cardiovascular outcomes.

$0.48,0.91 ; P_{\text {het }}=0.0002, I^{2}=88 \%$ ) (least adjusted RR 0.57; $95 \%$ CI $0.45,0.72$ ) (Fig. 5). After removing studies with an NOS score of $<7$, only one study remained with a relative risk estimate of $0.68(95 \% \text { CI } 0.60,0.77)^{(42)}$. The GRADE estimate for quality of evidence was very low $(\oplus \bigcirc \bigcirc)$ ).

CHD mortality. For CHD death, the summary multivariable RR for nut consumption in seven studies ${ }^{(14,21,22,40,45,47,54)}$ (ten subgroups), including 278584 participants (180 734 women) followed up for 5.4-30 years, experiencing a combined 8454 events, was 0.70 (95\% CI 0.64, 0.76; $P_{\text {het }}=0.65, I^{2}=0 \%$ ) (least adjusted RR $0.62 ; 95 \%$ CI $0.55,0.70)$. The estimates were similar in women and men $(0.69 ; 95 \%$ CI $0.59,0.82 v .0 .71$; $95 \%$ CI $0 \cdot 61,0.82$, respectively, $P_{\text {het }}=0.96, I^{2}=0 \%$ ) (Fig. 6). After removing studies with NOS scores below 7, four studies $^{(14,21,22,40)}$ remained and showed a risk estimate of 0.70 (95\% CI $0.62,0.78 ; P_{\text {het }}=0.32, I=15 \%$ ). The GRADE estimate for quality of evidence was moderate $(\oplus \oplus \oplus \mathrm{)})$.

Non-fatal CHD. In three prospective cohort studies ${ }^{(11,14,43)}$ involving 138678 participants experiencing 1565 non-fatal myocardial infarction events after 6-17 years of follow-up, the summary multivariable RR was 0.71 (95\% CI $0.49,1.03$; $P_{\text {het }}=0.03, I^{2}=72 \%$ ) (least adjusted RR $0.65 ; 95 \%$ CI 0.43 , $0.98)$, with sex explaining much of the heterogeneity. The RR in men was $1.04(95 \%$ CI $0.82,1.32)$ and in women it was 0.71 (95\% CI 0.47, 1.07; $P_{\text {het }}=0.12, I^{2}=59 \%$ ) (Fig. 7). In a mixed population of men and women, the RR was 0.49 (95\% CI $0 \cdot 28$, 0.85). No studies had NOS scores below 7. The GRADE estimate for quality of evidence was very low $(\oplus \bigcirc \bigcirc \bigcirc)$.

Sudden cardiac death. One study ${ }^{(11)}$ investigated the relationship between nut consumption and sudden cardiac death in 21454 men (201 events) over 17 years. The multivariable RR for sudden cardiac deaths was 0.53 (95\% CI 0.30, 0.93) (least adjusted RR $0.64 ; 95 \%$ CI $0.40,1.02)$. The GRADE estimate for the quality of evidence was very low $(\oplus \circ \bigcirc)$ ). The study is at a low risk for bias with a NOS score of 8 .

Total stroke. In two studies ${ }^{(13,23)}$ of 157826 participants and 4381 events accrued after 8.3-26 years of follow-up, the summary multivariable RR is 1.05 (95\% CI $0.69,1.61 ; P_{\text {het }}=0.04, I^{2}=77 \%$ ) (least adjusted RR 1.01; $95 \%$ CI 0.71, 1.44). One study compared the risk of stroke in women and in men $(0 \cdot 86 ; 95 \%$ CI 0.75, $0.98 v$. 0.92; $95 \%$ CI $0.77,1.09$, respectively; $\left.P_{\text {het }}=0.55, I^{2}=0 \%\right)$. The summary multivariable RR in three studies ${ }^{(13,23,49)}$ with 240508 participants and 3496 events investigating ischaemic stroke is 1.06 (95\% CI $0.81,1.38)$, whereas in one study ${ }^{(13)}$ investigating haemorrhagic stroke in 127160 people with 693 events the RR is 0.83 (95\% CI 0.59, 1.16) (Fig. 8). No studies had NOS scores below 7 . The GRADE estimate for quality of evidence was very low $(\oplus \bigcirc \bigcirc)$.

Stroke mortality. Three studies ${ }^{(22,23,40)}$ with four subgroups included 159322 participants and 2166 deaths after 8.3-30 years of follow-up. The summary multivariable RR was 0.83 (95\% CI $0.69,1.00 ; P_{\text {het }}=0.54, I^{2}=0 \%$ ) (least adjusted RR 0.70 ; $95 \%$ CI $0.58,0 \cdot 84)$. One study ${ }^{(40)}$ investigated men and women separately, and a non-significant trend for benefit was found in men $(0.78 ; 95 \%$ CI $0.58,1.05)$, whereas no evidence of association was found in women $(1.05 ; 95 \%$ CI $0.73,1.52)$. Another study ${ }^{(21)}$ compared the risk of haemorrhagic stroke $v$. ischaemic stroke $(1.21 ; 95 \%$ CI $0.63,2.33 v .0 .78 ; 95 \%$ CI 0.43 , 1.43 , respectively, $P_{\text {het }}=0.50, I^{2}=0 \%$ ) (Fig. 9). No studies had NOS scores below 7 . The GRADE estimate for quality of evidence was very low $(\oplus \circ \bigcirc \bigcirc)$.

Dose-response. Seven of the outcomes (all-cause mortality, total CVD, CVD mortality, CHD mortality, non-fatal CHD, sudden cardiac death and stroke mortality) had sufficient data to use generalised least squares for trend estimation analysis. Studies that did not provide the number of cases and number of 


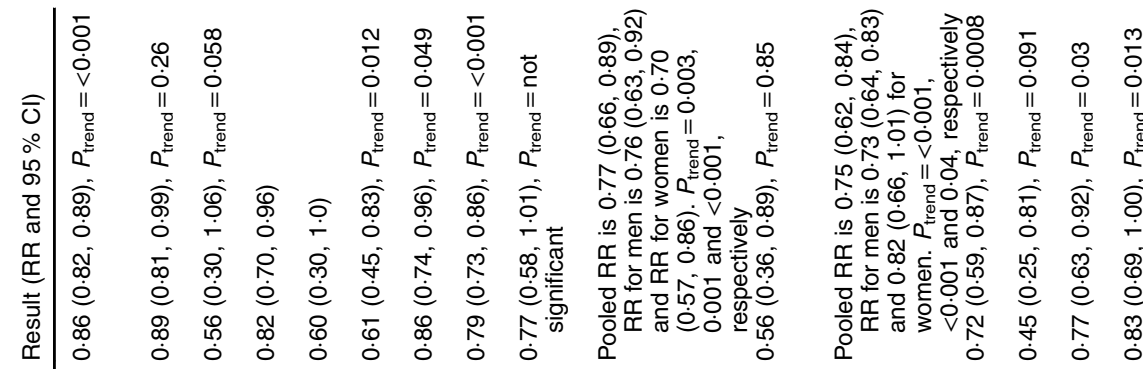

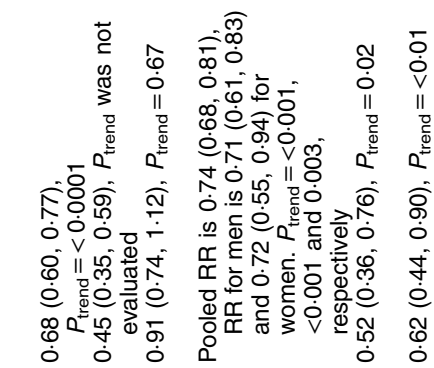

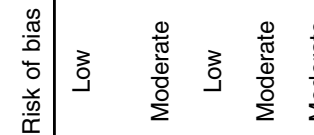

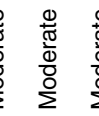

כ)

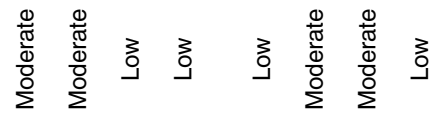

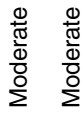

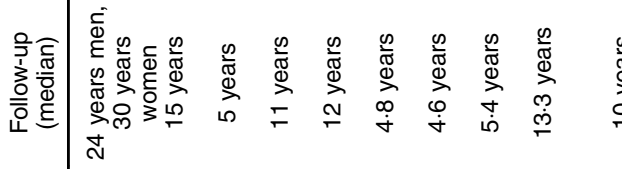

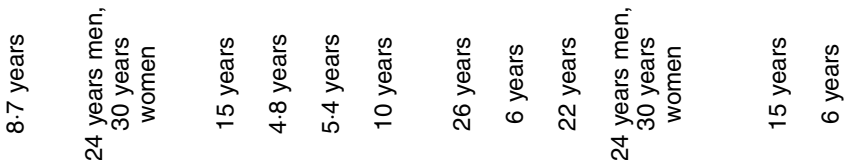

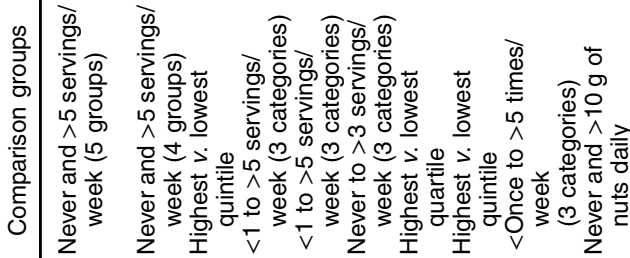

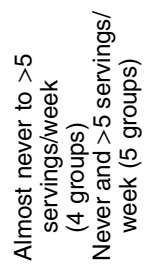

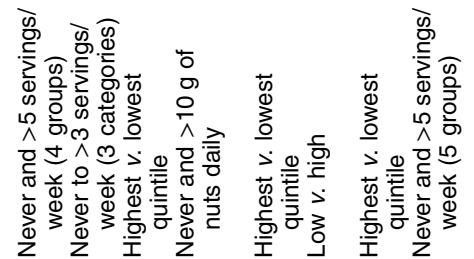

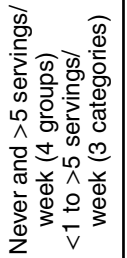

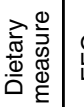

o

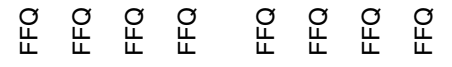

운 운

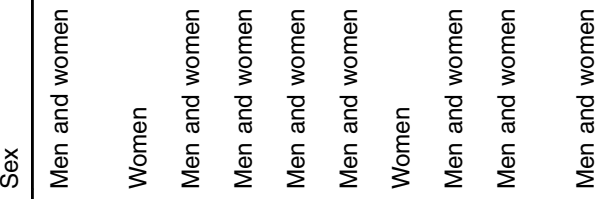

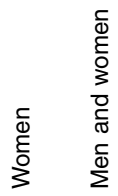

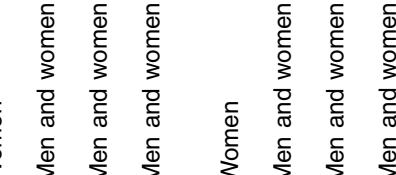

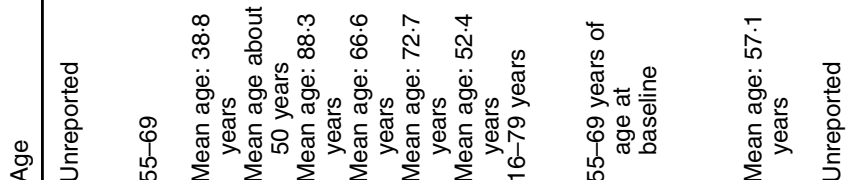

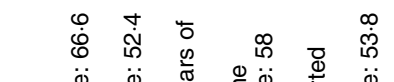

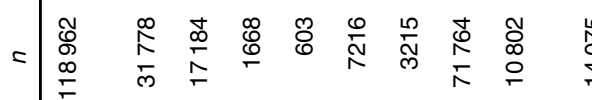

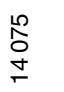

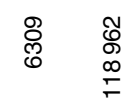

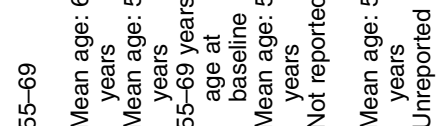

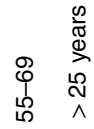

言总

凹

跑离

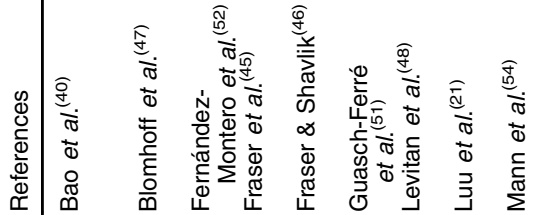

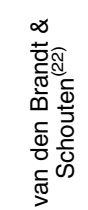

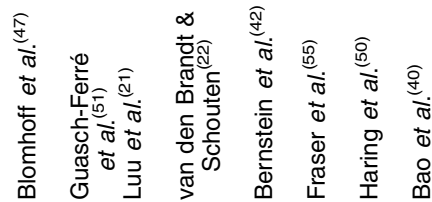

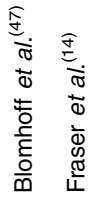

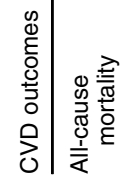

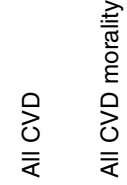

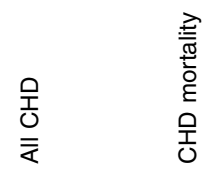




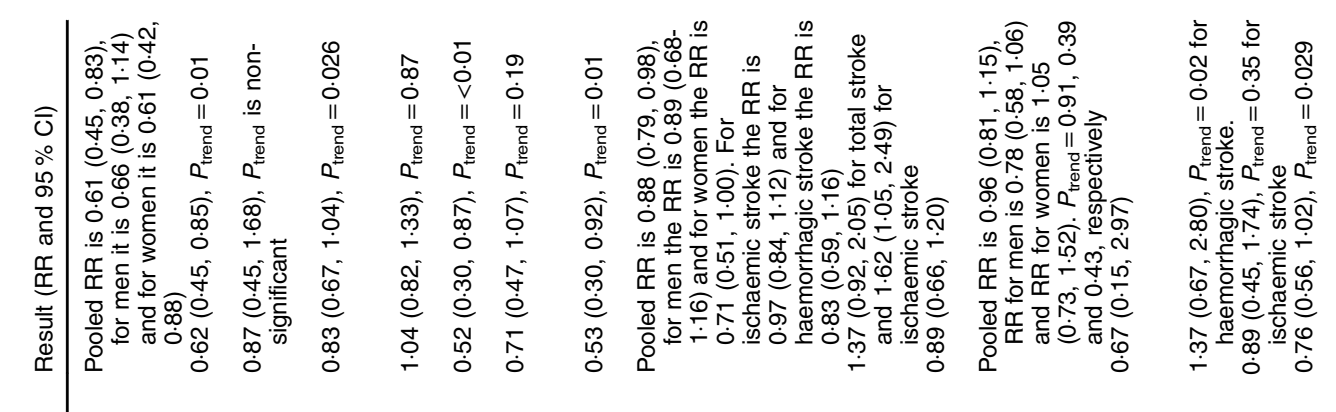

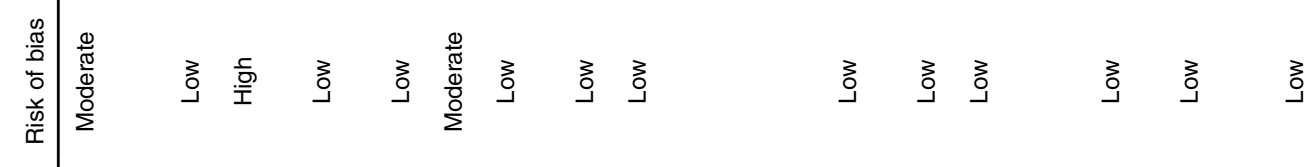

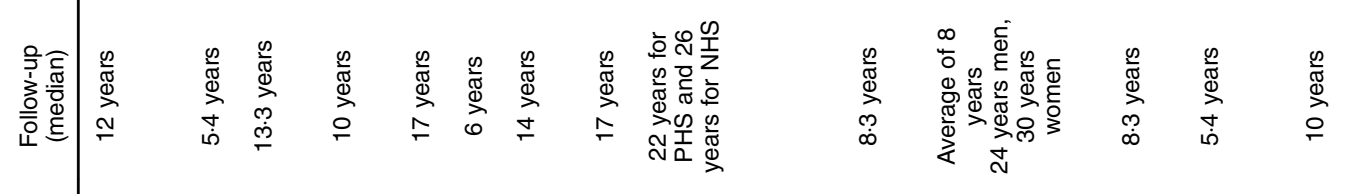

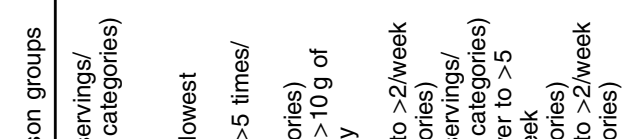

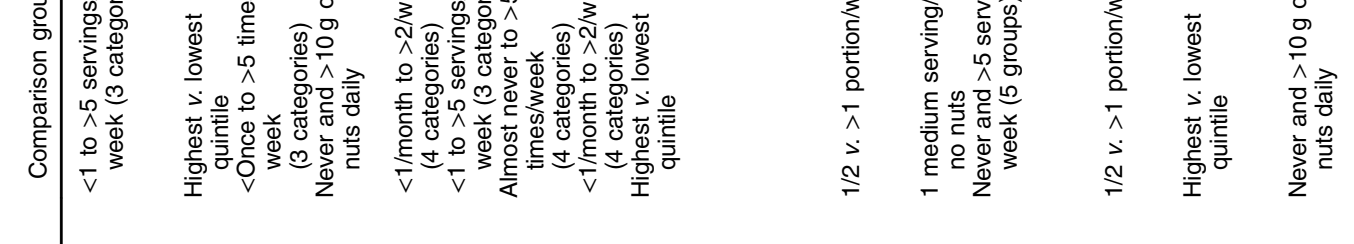

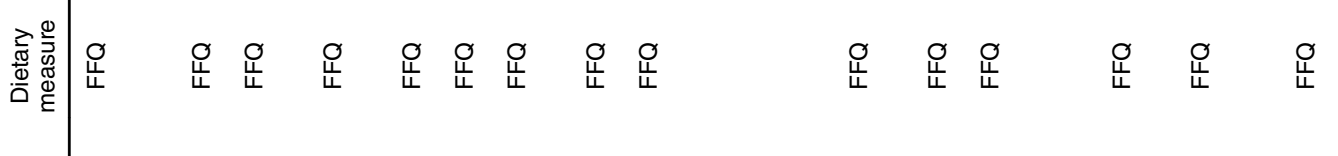

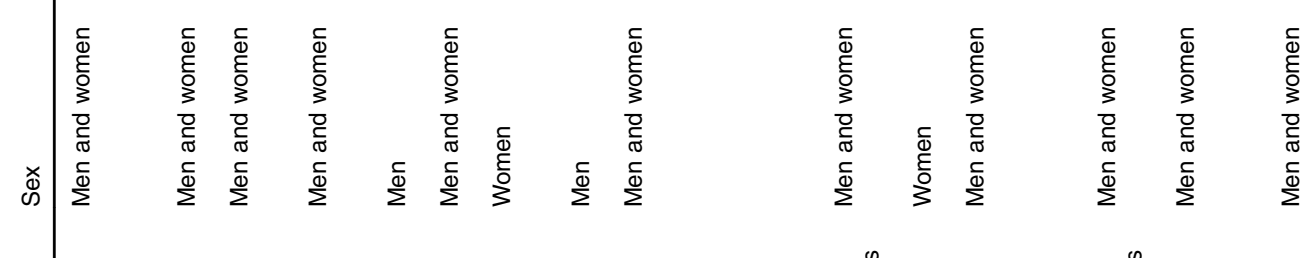

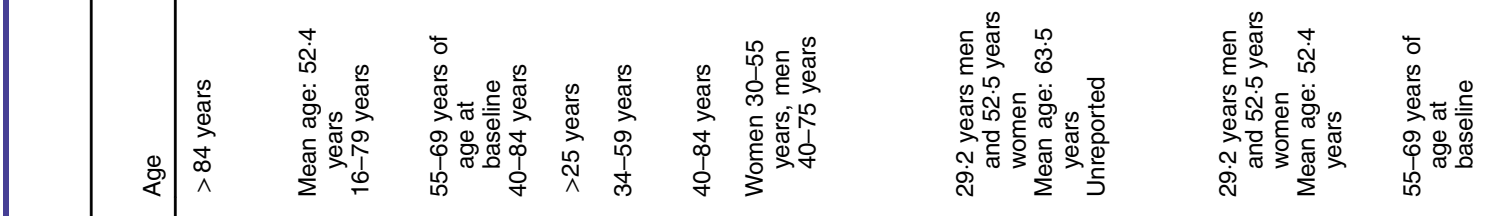

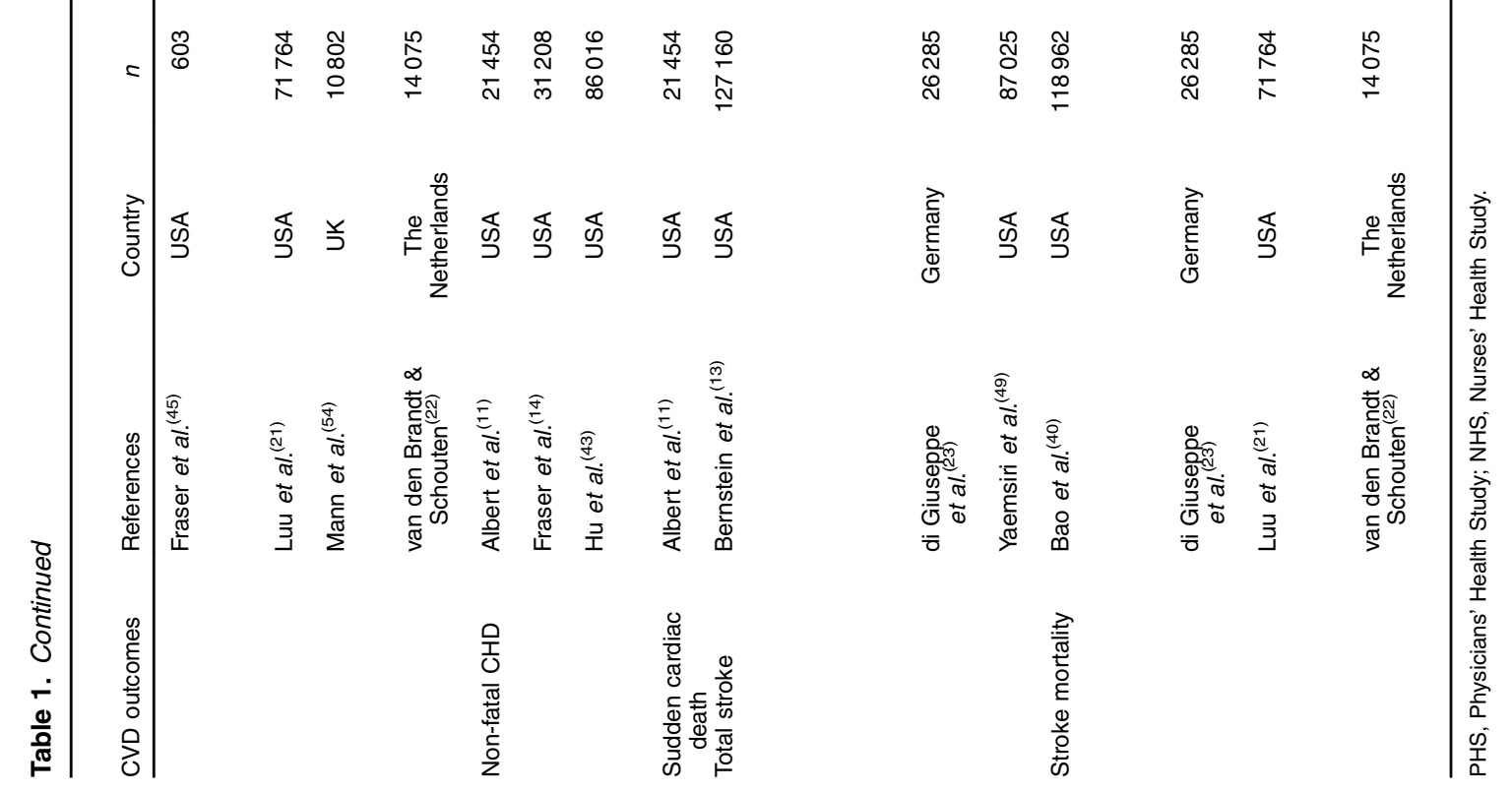




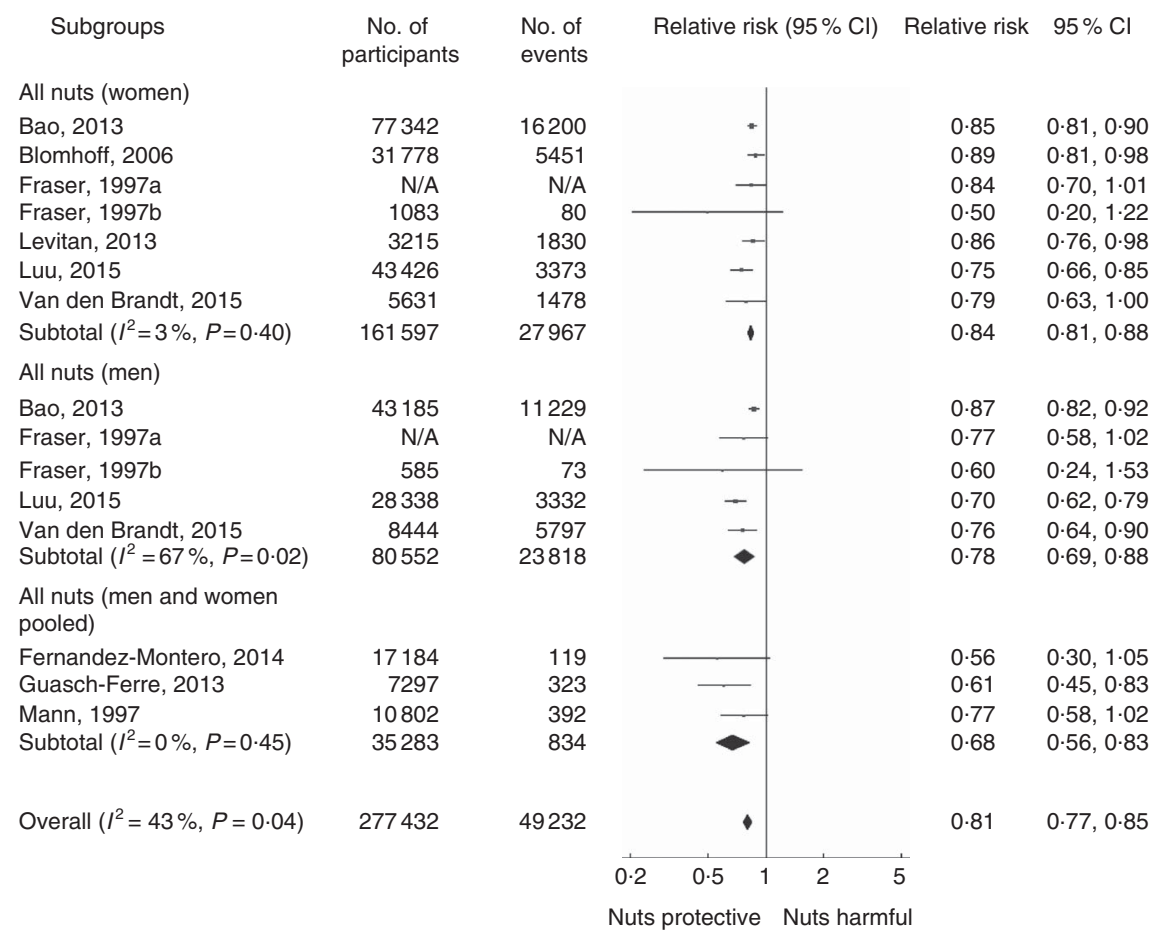

Fig. 3. Meta-analysis of the association between nut consumption and all-cause mortality.

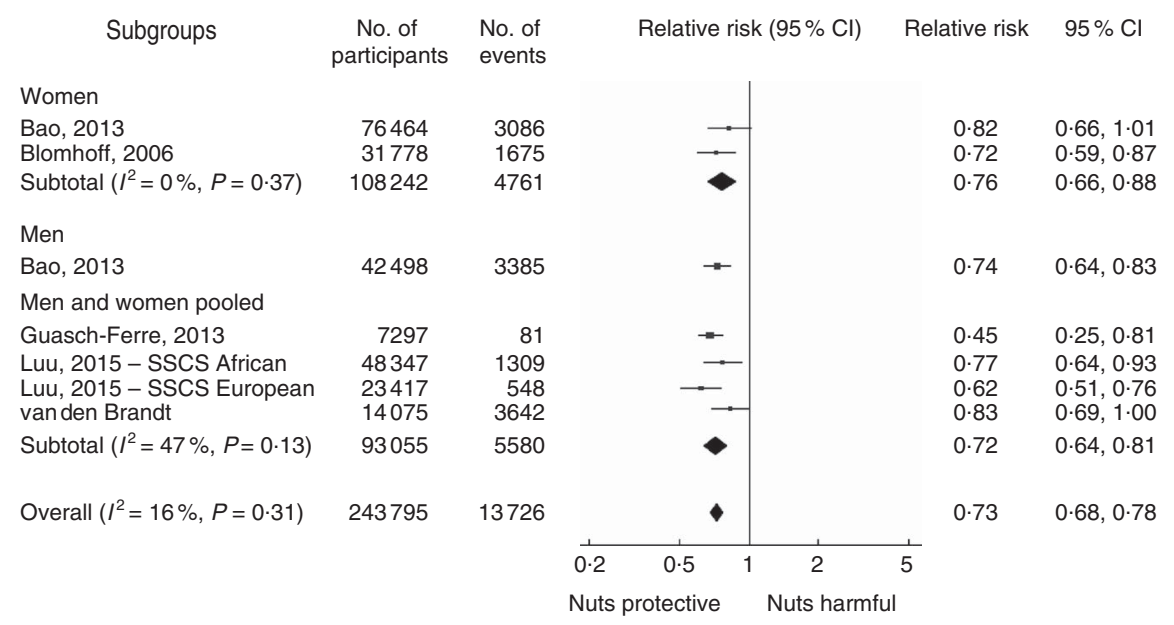

Fig. 4. Meta-analysis of the association between nut consumption and CVD mortality.

person-years of follow-up were excluded. Significant reductions in risk per 4 weekly servings were seen for all-cause mortality (0.81; 95\% CI $0.75,0.92)$, total CVD $(0.72 ; 95 \%$ CI $0.55,0.96)$, non-fatal CHD $(0.81 ; 95 \%$ CI $0.72,0.96)$ and sudden cardiac death $(0.71 ; 95 \%$ CI $0.55,0.93)$. A statistically non-significant reduction in risk of CVD mortality $(0.78 ; 95 \%$ CI $0.63,1.00)$, CHD mortality $(0.78 ; 95 \%$ CI $0.57,1.08)$ and stroke mortality (0.85; $95 \%$ CI $0.55,1 \cdot 31)$ was found.

Types of nuts. Five studies reported on different types of nut consumption ${ }^{(21,22,40,43,51)}$. Guasch-Ferré et al. ${ }^{(51)}$ reported on walnut consumption $v$. CVD death and all-cause mortality. Hu et $a l^{(43)}$ reported on peanut consumption $v$. total CHD. Bao et $a l^{(40)}$ reported peanut intake $v$. all-cause mortality, CHD mortality and stroke mortality. Van den Brandt \& Schouten reported on the same outcomes, as well as CVD mortality for peanut consumption, and Luu et al. reported on the same outcomes using data from the Shanghai Men's and Women's Health Studies ${ }^{(21,22)}$. Peanut consumption was associated with a significantly reduced risk of all-cause mortality (0.86; $95 \%$ CI 0.82 , $0.90)$, CVD mortality (0.77; $95 \%$ CI $0.70,0.85)$, total CHD (0.66; $95 \%$ CI $0.46,0.94)$ and CHD mortality $(0 \cdot 76 ; 95 \%$ CI 0.69, 0.83), 


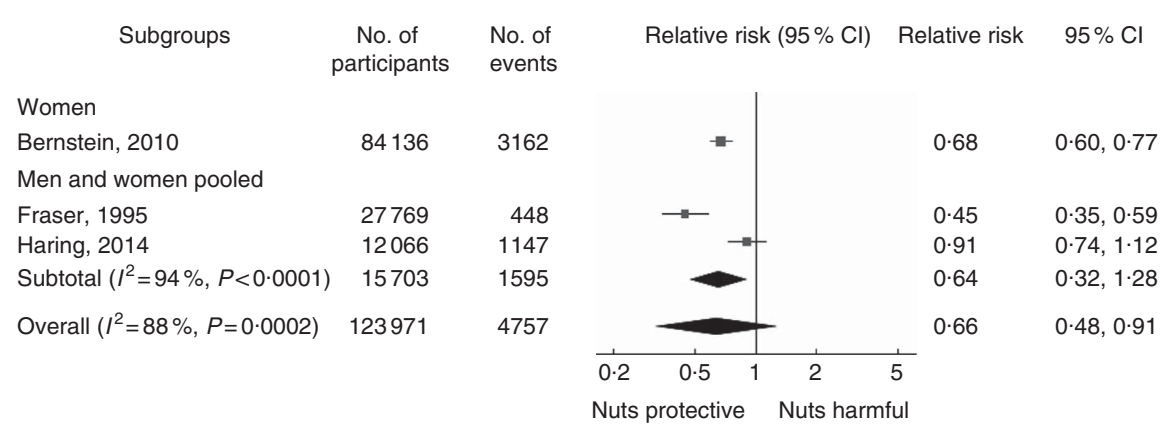

Fig. 5. Meta-analysis of the association between nut consumption and total $\mathrm{CHD}$.

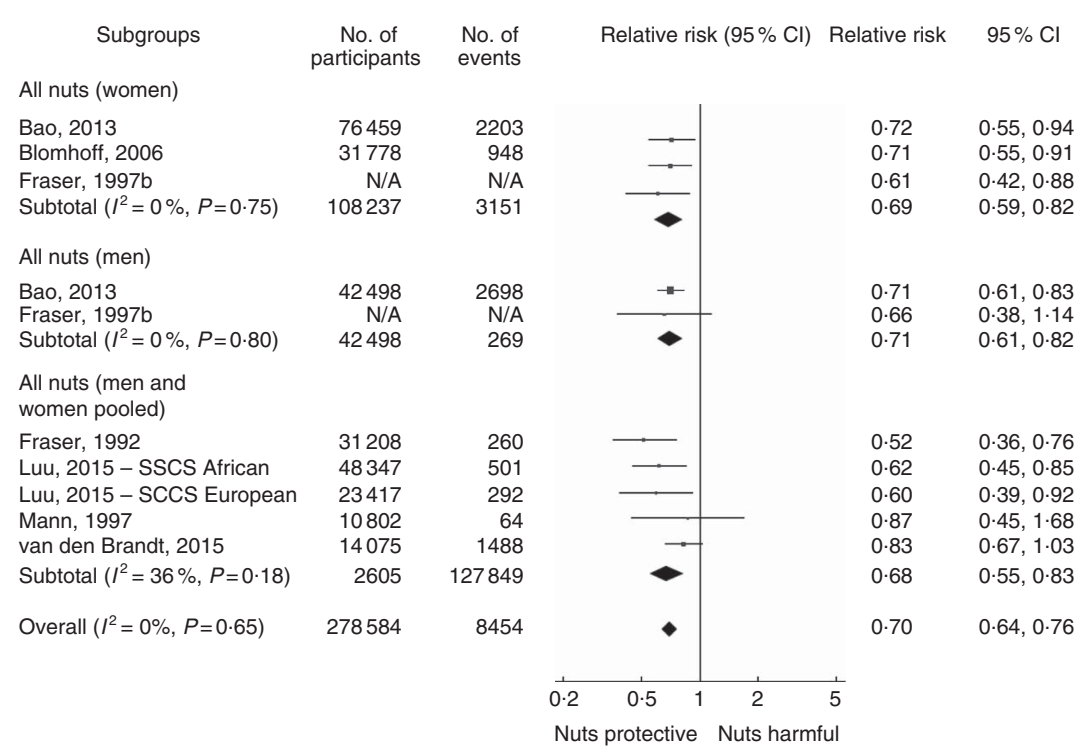

Fig. 6. Meta-analysis of the association between nut consumption and $\mathrm{CHD}$ mortality.

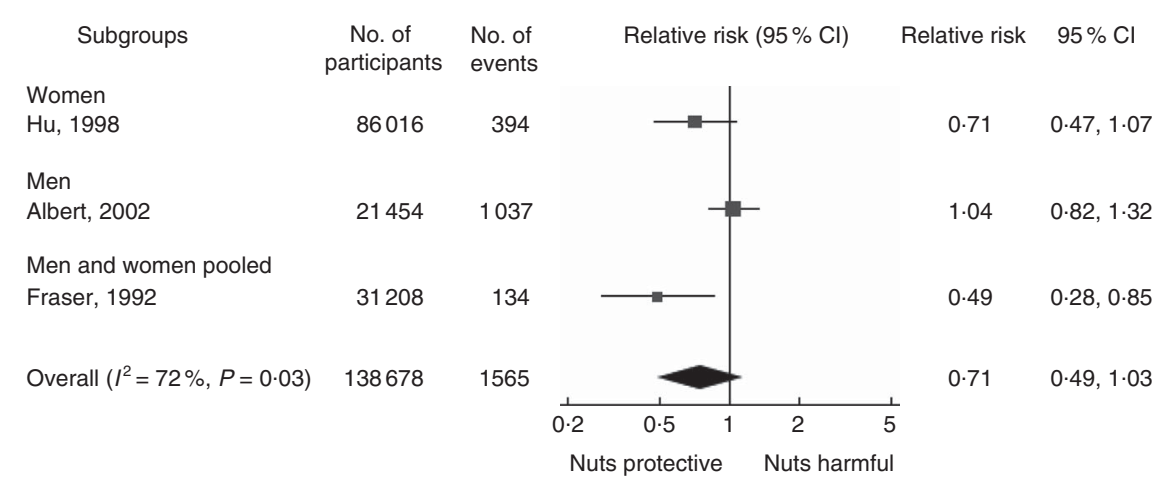

Fig. 7. Meta-analysis of the association between nut consumption and non-fatal CHD.

and a non-significant trend was found for stroke mortality (0.81; $95 \%$ CI $0 \cdot 60,1 \cdot 10)$. Walnut consumption was associated with a significantly reduced risk of all-cause mortality $(0.55 ; 95 \% \mathrm{CI}$ $0.40,0.76)$ and CVD mortality (0.53; $95 \%$ CI 0.29, 0.97) (online Supplementary Appendix S5).

Geographic location. Three outcomes had two or more studies conducted in both the USA and Europe. No studies were conducted on other continents. We explored heterogeneity by continent. For all-cause mortality, the summary multivariable RR was 0.83 (95\% CI $\left.0.77,0.89 ; P_{\text {het }}=0.01, I^{2}=67 \%\right)$ in the USA and 0.73 (95\% CI 0.65 , $\left.0.83 ; P_{\text {het }}=0.45, I^{2}=0 \%\right)$ in Europe. For CVD mortality, the RR was 0.73 (95\% CI $\left.0.67,0.81 ; P_{\text {het }}=0.67, I^{2}=0 \%\right)$ in the USA and 0.65 (95\% CI 0.36, 1.17; $P_{\text {het }}=0.05, I^{2}=74 \%$ ) in Europe. For CHD mortality, the relative risk was $0.69\left(95 \% \mathrm{CI} 0.62,0.76 ; P_{\text {het }}=0.33\right.$, $\left.I^{2}=18 \%\right)$ in the USA and $0.83\left(95 \%\right.$ CI $0.68,1.02 ; P_{\text {het }}=0.89$, $I^{2}=0 \%$ ) in Europe (online Supplementary Appendix S6).

Publication bias. Because of the small number of studies for each outcome, the risk of publication bias could only be assessed for 


\begin{tabular}{|c|c|c|c|c|c|}
\hline Subgroups & $\begin{array}{c}\text { No. of } \\
\text { participants }\end{array}$ & $\begin{array}{l}\text { No. of } \\
\text { events }\end{array}$ & Relative risk $(95 \% \mathrm{Cl})$ & Relative risk & $95 \% \mathrm{Cl}$ \\
\hline \multicolumn{6}{|l|}{$\begin{array}{l}\text { Ischaemic and haemorrhagic } \\
\text { Stroke - men and women } \\
\text { pooled }\end{array}$} \\
\hline \multirow{3}{*}{$\begin{array}{l}\text { Bernstein, } 2012 \\
\text { di Giuseppe, } 2015 \\
\text { Overall (pooled stroke) } \\
\left(I^{2}=77 \%, P=0 \cdot 04\right)\end{array}$} & 127160 & 4030 & - & 0.88 & $0.79,0.98$ \\
\hline & 26285 & 288 & & 1.37 & $0.92,2.05$ \\
\hline & 153445 & 4318 & & 1.05 & $0.69,1.61$ \\
\hline \multicolumn{6}{|l|}{ Ischaemic stroke } \\
\hline Bernstein, 2012 & 127251 & 2212 & & 0.97 & $0 \cdot 84,1 \cdot 12$ \\
\hline \multirow{2}{*}{$\begin{array}{l}\text { di Giuseppe, } 2014 \\
\text { Yaemsiri, } 2012 \\
\text { Overall (ischaemic stroke) } \\
\left(I^{2}=64 \%, P=0.06\right)\end{array}$} & $\begin{array}{l}26232 \\
87025\end{array}$ & $\begin{array}{r}235 \\
1049\end{array}$ & $\ldots$ & $\begin{array}{l}1.62 \\
0.89\end{array}$ & $\begin{array}{l}1 \cdot 05,2.49 \\
0.66 .1 .20\end{array}$ \\
\hline & $\begin{array}{r}87025 \\
240508\end{array}$ & $\begin{array}{l}1049 \\
3496\end{array}$ & & $\begin{array}{l}0.89 \\
1.06\end{array}$ & $0.81,1.38$ \\
\hline \multicolumn{6}{|l|}{ Haemorrhagic stroke } \\
\hline Bernstein, 2012 & & & $\begin{array}{lll}1 & 1 & 1 \\
0.5 & 1 & 2\end{array}$ & 5 & \\
\hline
\end{tabular}

Fig. 8. Meta-analysis of the association between nut consumption and total stroke.

\begin{tabular}{|c|c|c|c|c|c|}
\hline Subgroups & $\begin{array}{c}\text { No. of } \\
\text { participants }\end{array}$ & $\begin{array}{l}\text { No. of } \\
\text { events }\end{array}$ & Relative risk $(95 \% \mathrm{Cl}$ ) & Relative risk & $95 \% \mathrm{Cl}$ \\
\hline \multicolumn{6}{|l|}{$\begin{array}{l}\text { All stroke types - men and } \\
\text { women pooled }\end{array}$} \\
\hline $\begin{array}{l}\text { Di Giuseppe, } 2015 \\
\text { van den Brandt, } 2015\end{array}$ & $\begin{array}{l}26285 \\
14075\end{array}$ & $\begin{array}{r}36 \\
565\end{array}$ &. & $\begin{array}{l}0.67 \\
0.76\end{array}$ & $\begin{array}{l}0 \cdot 15,2 \cdot 98 \\
0.56,1.03\end{array}$ \\
\hline Subtotal $\left(I^{2}=0 \%, P=0.87\right)$ & 40360 & 601 & - & 0.76 & $0.56,1 \cdot 01$ \\
\hline \multicolumn{6}{|l|}{ All stroke types - women } \\
\hline Bao, 2013 & 76464 & 878 & - & 1.05 & $0.73,1.52$ \\
\hline \multicolumn{6}{|l|}{ All stroke types - men } \\
\hline Bao, 2013 & 42298 & 687 & $\rightarrow$ & 0.78 & $0.58,1.05$ \\
\hline $\begin{array}{l}\text { Overall (all types of stroke) } \\
\left(I^{2}=0 \%, P=0.54\right)\end{array}$ & 159322 & 2166 & $\bullet$ & 0.83 & $0.69,1.00$ \\
\hline \multicolumn{6}{|l|}{$\begin{array}{l}\text { Haemorrhagic stroke - men } \\
\text { and women pooled }\end{array}$} \\
\hline Luu, 2015 - SSCS African & 48347 & 75 & - & 1.37 & $0.67,2 \cdot 80$ \\
\hline Luu, 2015 - European & 23417 & 21 & & 0.62 & $0 \cdot 12,3 \cdot 23$ \\
\hline $\begin{array}{l}\text { Overall (haemorrhagic } \\
\text { stroke) }\left(I^{2}=0 \%, P=0.39\right)\end{array}$ & 71764 & 96 & & $1 \cdot 21$ & $0 \cdot 63,2 \cdot 33$ \\
\hline \multicolumn{6}{|l|}{$\begin{array}{l}\text { Ischaemic stroke - men } \\
\text { and women pooled }\end{array}$} \\
\hline Luu, 2015 - SSCS African & 48347 & 96 & - & 0.89 & $0.45,1.75$ \\
\hline Luu, 2015 - European & 23417 & 25 & — & 0.47 & $0 \cdot 12,1 \cdot 80$ \\
\hline \multirow{2}{*}{$\begin{array}{l}\text { Overall (ischaemic stroke) } \\
\left(I^{2}=0 \%, P=0.41\right)\end{array}$} & 71764 & 121 & - & 0.78 & $0.43,1 \cdot 43$ \\
\hline & & & \multicolumn{2}{|c|}{ Nuts protective Nuts harmful } & \\
\hline
\end{tabular}

Fig. 9. Meta-analysis of the association between nut consumption and stroke mortality

all-cause mortality ${ }^{(56)}$. Visual inspection of the funnel plot suggested asymmetry with the tendency for the publication of small and/or imprecise studies to favour nuts (online Supplementary Appendix S7). Both Egger's and Begg's tests suggested publication bias (Egger's $P=0 \cdot 006$; Begg's $P=0 \cdot 067$ ). However, the trim and fill method did not remove any studies or indicate that there were any studies missing.

\section{Retrospective studies}

One study from India ${ }^{(57)}$ compared the odds of consuming nuts in hospitalised myocardial infarction patients in comparison with community controls. Of the 500 participants ( 407 men and ninety-three women), 205 of the men and forty-five of the women were cases. The fully adjusted OR was not provided for men, and it was 10.9 (95\% CI 2.49, 48.2) for women. The least adjusted OR was 2.02 (95\% CI 1.24, 3.30) in men and $9.11(95 \%$ CI $2 \cdot 22,43 \cdot 28)$ in women. The study is at a high risk for bias with an NOS score of 5 .

\section{Discussion}

In this systematic review of twenty prospective cohort studies involving 467389 participants and 13226 CVD outcomes including 10120 deaths from CVD, comparing highest with lowest nut consumers, we found that nut consumption was associated with a $19 \%$ lower risk of all-cause mortality, a $44 \%$ lower risk of total CVD, a $27 \%$ lower risk of death from any type of CVD, a $34 \%$ 
lower risk of all CHD, a $30 \%$ lower risk of CHD mortality and a $47 \%$ lower risk of sudden cardiac death, as well as a statistically non-significant reduction in risk of non-fatal CHD by $29 \%$ and stroke mortality by $17 \%$. Further, a 4 -weekly servings increment in nut intake, an amount consistent with the DASH $\operatorname{diet}^{(34)}$, was associated with a $19 \%$ lower risk of all-cause mortality, a $28 \%$ lower risk of total CVD, a $19 \%$ lower risk of non-fatal CHD, a $75 \%$ lower risk of sudden cardiac death and a statistically non-significant reduction in CVD mortality by $22 \%$, CHD mortality by $22 \%$ and stroke mortality by $15 \%$. No evidence of association between nut intake and total stroke was found, but the quality of evidence was very low for this outcome. The estimates across studies were homogeneous for each outcome, except for total CHD, non-fatal CHD and total stroke. Of the statistically significant outcomes, all-cause mortality, total CVD and CHD mortality had a moderate quality of evidence. Taken together, our findings are compatible with findings of previous systematic reviews that similarly found evidence of an inverse association of nut consumption with all-cause mortality ${ }^{(15,19)}$, total CVD $^{(16,19)}$, CVD mortality ${ }^{(15)}$, total $\mathrm{CHD}^{(19,20)}$, CHD mortality ${ }^{(18)}$ and non-fatal $\mathrm{CHD}^{(18)}$ and no evidence of association for total stroke ${ }^{(18-20)}$.

The role of nuts as part of a healthy diet is not well emphasised in most guidelines. For example, the World Health Organization ${ }^{(58)}$ states that the evidence supporting unsalted nuts for decreasing CVD risk is 'probable', but the quality of the evidence underlying this statement was not evaluated using GRADE criteria. The American Heart Association's dietary guidelines simply refer to nuts as part of the DASH diet ${ }^{(59)}$. The Canada Food Guide states that $60 \mathrm{ml}$ of nuts makes up a serving of 'meat and alternatives' with no other information provided ${ }^{(60)}$. The 2010 Dietary Guidelines for Americans provide the most detail on the possible benefits of nuts, stating that they are a nutrient-dense, high-fibre food and a good source of protein, and provide a recommended intake of 4 ounces of nuts (and seeds/soya products)/week for a $8368 \mathrm{~kJ}$ (2000-kcal) $\operatorname{diet}^{(61)}$. Nonetheless, these 2010 guidelines state that 'moderate' evidence exists on nut consumption and reduced CVD risk factors, indicating a need to consider the most updated evidence on nut consumption and CVD outcomes, which if warranted may prompt organisations to place greater emphasis on nut consumption. In some regions of the world where contamination with aflatoxins is common, it may not be appropriate to recommend increased nut consumption for populations ${ }^{(62)}$.

Our findings of an inverse association between nut consumption and CVD outcomes are consistent with meta-analyses of observational studies ${ }^{(15-20,63-67)}$ and $\operatorname{RCT}^{(9,68-70)}$ showing that following a Mediterranean diet that includes nuts is related to a lower risk of CVD. However, there are currently no clinical trials that independently assess nut consumption and CVD outcomes. In the absence of randomised trials, we focused on the available epidemiologic data. Although nut consumption is inversely associated with several outcomes (total CVD, CVD mortality, CHD mortality, sudden cardiac death), the strongest association is found for total CVD and CHD mortality. The main data sources on nut intake and CVD events come from five cohorts: the Adventist Health Study ${ }^{(14,45,46)}$, the Nurses' Health Study ${ }^{(13,40-43)}$, Physicians' Health Study ${ }^{(11,13,40,44)}$, the Iowa Women's Health Study ${ }^{(28)}$ and the Southern Community Cohort Study ${ }^{(21)}$. These cohorts have a prolonged follow-up (4-30 years), large sample size
(31 208-86 016 participants) and assessed populations living in the USA. Of these studies, the Adventist Health Study is unique in that it focused on a population that largely abstains from alcohol and tobacco and frequently follows a lacto-vegetarian diet, whereas the Southern Community Cohort Study recruited participants at an elevated risk of cancer including individuals with low incomes, African-Americans and people from rural settings. Nevertheless, each found a significant inverse association between nut intake and CVD outcomes, with a pooled relative risk of 0.73 (95\% CI $0.68,0.78$ ) for nut consumption and CVD mortality. There are also numerous clinical trials investigating the effect of nuts on CVD surrogate measures ${ }^{(10)}$. Collectively, these showed beneficial effects on LDL-cholesterol, ratio of LDL:HDL-cholesterol, total cholesterol and $\mathrm{TAG}^{(71,72)}$. Taken together, the evidence from observational studies of health outcomes and clinical trials of surrogate measures indicates a consistent role of nuts in a heart-healthy diet.

There are a number of dietary constituents in nuts that may explain their observed beneficial associations with multiple causes of mortality. Despite almost $80 \%$ of energy coming from fat ${ }^{(73)}$, nuts are low in SFA (4-16\%) and high in both monounsaturated and polyunsaturated fat, which have beneficial effects on inflammation, lipid markers, blood pressure and are inversely associated with CVD outcomes ${ }^{(7,74-77)}$. Nuts also are a good source of many micronutrients that are individually associated with decreases in CVD risk including folate, antioxidant vitamins and compounds, plant sterols, $\mathrm{Ca}, \mathrm{Mg}$ and $\mathrm{K}^{(7)}$. In addition, increased nut consumption may displace intake of less healthy foods such as highly refined sugars and starches, reducing glycaemic load and risk of CVD, other chronic diseases including cancer and all-cause mortality ${ }^{(78)}$. Therefore, the finding of benefit with nut intake that is nonspecific to a single outcome is in keeping with its impact on a wide range of aetiologies and physiologic pathways.

We found limited data on the effects of different types of nuts (e.g. peanuts and tree nuts including almonds, hazelnuts, walnuts and pistachios) on mortality and CVD risk, which precluded an assessment of their association with most CVD outcomes. Three studies ${ }^{(21,22,40)}$ showed an association of peanut consumption with a lower risk of all-cause mortality and CHD mortality. Two of those studies ${ }^{(21,22)}$ also showed an inverse association of peanut consumption with CVD mortality, whereas one study ${ }^{(43)}$ found an inverse association with total CHD. Two studies providing data on stroke mortality ${ }^{(22,40)}$ did not find evidence of an association. The relative risk estimates for peanut consumption and these outcomes were similar to those found in the meta-analysis for all nuts. Walnuts were also associated with a lower risk of all-cause mortality and CVD mortality ${ }^{(51)}$, although the relative risk estimates were markedly lower than the summary relative risk estimates for all nuts. However, the relative risk estimates for all-cause mortality and CVD mortality for all types of nuts excluding walnuts within the same study were similarly lower compared with the summary relative risk estimates for all other studies. This indicates that the lower relative risk estimates for walnuts may be reflective of study differences rather than the effect of walnuts. We also found a minimal impact of sex or study quality on the relative risk estimates for all outcomes. Owing to the small number of available studies, our analyses of the effect of nuts on different types of stroke (haemorrhagic $v$. ischaemic stroke) were 
inconclusive. Larger studies providing data on the associations between different types of nuts and total and stroke subtypes are needed.

In our analyses by geographic region, the estimates for the association between nut intake and outcomes were not materially different in North America compared with Europe. This assessment is limited by the small number of studies for each geographic region (two to five), as well as the small number of outcomes with sufficient data to analyse. In addition, these findings may not be generalisable to geographic regions outside of North America and Europe, particularly to low- and middle-income countries where there are different types of nuts available and varying dietary patterns. Further work is needed in these regions.

This study has several strengths. First, a thorough systematic search of the literature was conducted, with each study evaluated for the risk of bias. Second, retrospective observational designs (e.g. case-control studies) were excluded, given their limitations in assessing dietary effects on long-term clinical outcomes. Third, the quality of the evidence was evaluated using the GRADE approach to help facilitate translation of our findings into guidelines. Last, the quantitative synthesis was focused on studies measuring comparable outcomes using similar designs, reducing methodological heterogeneity.

This study also has some limitations. Measurement error in assessing dietary intake may dilute associations towards the null, resulting in attenuated associations between nut consumption and CVD outcomes. Second, because of a modest number of cohorts, dose-response relationships or differences between key subgroups (based on age, sex, geographic region, measurement tools) could not be robustly quantified. Third, data on two outcomes (total CVD and sudden cardiac death) were available only from an individual cohort study for each, which precludes performing meta-analyses for these outcomes. Fourth, the lack of available data did not allow us to adequately assess the association of individual types of nuts (e.g. peanuts $v$. tree nuts) with CVD outcomes or the effect of salted $v$. unsalted nuts. Fifth, because of the small number of studies identified, we could not statistically assess the potential for publication bias for any outcome but allcause mortality. Given that only eleven large prospective cohorts are represented, it is possible that unpublished data may exist, or that an important literature published in non-English language journals was missed by our search strategy. A visual inspection of the funnel plot and Egger's and Begg's tests suggested possible publication bias. However, the trim and fill method did not detect any missing studies, which suggests that publication bias may be present but that our findings are minimally affected by publication bias. Last, our analysis used the most-adjusted multivariable models to compute summary estimates of association. We attempted to assess the potential impact of over-adjustment; however, only four studies included intermediately adjusted models' - that is those that adjusted for the most-relevant confounders (smoking, age, sex and total energy), but not potential causal intermediates (blood pressure or anti-hypertensive medications, serum lipids or lipid-lowering medications). Models adjusted for both potential confounders and intermediate variables are more likely to provide a conservative estimate of association because of possible over-adjustment for the effect of causal intermediates $^{(79,80)}$.

\section{Conclusions}

This systematic review and meta-analysis of large, generally well-designed prospective cohort studies showed that nut consumption is inversely associated with all-cause mortality, total CVD, CVD mortality, total CHD, CHD mortality and sudden cardiac death, and a statistically non-significant reduction in risk of non-fatal CHD and stroke mortality. No evidence of an association between nut intake and total stroke was found, but the quality of evidence for this outcome was very low. We judged the quality of evidence as moderate for all-cause mortality, CVD mortality and CHD mortality, as low for total CVD and sudden cardiac death and as very low for total CHD, nonfatal CHD, total stroke and stroke mortality. Our study supports the statement that higher nut consumption is associated with a decreased risk of CVD events and all-cause mortality. More data are needed on the effects of individual types of nuts on CVD outcomes and mortality, and in populations outside North America and Europe.

\section{Acknowledgements}

None.

A. J. M. is the recipient of an Ontario Graduate Scholarship. R. J. d. S. is the recipient of a Canadian Institutes of Health Research postdoctoral fellowship, and he has received research support from the Canadian Foundation for Dietetic Research, the Calorie Control Council (investigator-initiated, unrestricted) and the Coca-Cola Company (investigator-initiated, unrestricted). D. M. holds a Canada Research Chair in Genetics of Obesity. A. M. is a recipient of a Research Early Career Award from Hamilton Health Sciences Foundation. S. S. A. is a recipient of the Heart and Stroke Michael G. DeGroote Chair in Population Health Research and a Canada Research Chair in Ethnicity and Cardiovascular Disease.

A. J. M., A. M. and R. J. d. S. designed the research question. A. J. M. and R. J. d. S. conducted the research. A. J. M. and R. J. d. S. analysed the data and performed the statistical analysis. A. J. M., R. J. d. S., S. S. A., D. M. and A. M. wrote the paper. A. M. had primary responsibility for the final content. All authors read and approved the final manuscript.

The authors declare that there are no conflicts of interest.

\section{Supplementary material}

For supplementary material/s referred to in this article, please visit http://dx.doi.org/doi:10.1017/S0007114515004316

\section{References}

1. Deaton C, Froelicher ES, Wu LH, et al. (2011) The global burden of cardiovascular disease. J Cardiovasc Nurs. 26, S5-S14.

2. Taylor F, Huffman MD, Macedo AF, et al. (2013) Statins for the primary prevention of cardiovascular disease. The Cochrane Database of Systematic Reviews 2008, issue 1, CD004816. http://onlinelibrary.wiley.com/doi/10.1002/14651858.CD0048 16.pub5/abstract

3. Carter AA, Gomes T, Camacho X, et al. (2013) Risk of incident diabetes among patients treated with statins: population based study. BMJ 23, f2610. 
4. Chiuve SE, Rimm EB, Sandhu RK, et al. (2012) Dietary fat quality and risk of sudden cardiac death in women. Clin Nutr 96, 498-507.

5. Mozaffarian D, Ascherio A, Hu FB, et al. (2005) Interplay between different polyunsaturated fatty acids and risk of coronary heart disease in men. Circulation 111, 157-164.

6. Johnson RK, Black AE \& Cole TJ (1998) Dietary fat intake and the risk of coronary heart disease in women. $N$ Engl J Med 338, 918-919.

7. Ros E (2010) Health benefits of nut consumption. Nutrients $\mathbf{2}$, 652-682.

8. Estruch R, Ros E, Salas-Salvadó J, et al. (2013) Primary prevention of cardiovascular disease with a Mediterranean diet. N Engl J Med 368, 1279-1290.

9. De Lorgeril M, Salen P, Martin J-L, et al. (1999) Mediterranean diet, traditional risk factors, and the rate of cardiovascular complications after myocardial infarction: final report of the Lyon Diet Heart Study. Circulation 99, 779-785.

10. Kris-Etherton PM, Hu FB, Ros E, et al. (2008) The role of tree nuts and peanuts in the prevention of coronary heart disease: multiple potential mechanisms. J Nutr 138, 1746S-1751S.

11. Albert CM, Faziano MJ, Willett WC, et al. (2002) Nut consumption and decreased risk of sudden cardiac death in the Physicians' Health Study. Arch Intern Med 162, 1382-1387.

12. Baer HJ, Glynn RJ, Hu FB, et al. (2011) Risk factors for mortality in the Nurses' Health Study: a competing risks analysis. $A m J$ Epidemiol 173, 319-329.

13. Bernstein AM, Pan A, Rexrode KM, et al. (2012) Dietary protein sources and the risk of stroke in men and women. Stroke $\mathbf{4 3}$, 637-644.

14. Fraser GE, Sabaté J, Beeson WL, et al. (1992) A possible protective effect of nut consumption on risk of coronary heart disease. Arch Intern Med 152, 1416-1424.

15. Grosso G, Yang J, Marventano S, et al. (2015) Nut consumption on all-cause, cardiovascular, and cancer mortality risk: a systematic review and meta-analysis of epidemiologic studies. Am J Clin Nutr 101, 783-793.

16. Ma L, Wang F, Guo W, et al. (2014) Nut consumption and the risk of coronary artery disease: a dose-response meta-analysis of 13 prospective studies. Thromb Res 134, 790-794.

17. Shi ZQ, Tang JJ, Wu $\mathrm{H}$, et al. (2014) Consumption of nuts and legumes and risk of stroke: a meta-analysis of prospective cohort studies. Nutr Metab Cardiovasc Dis 24, 1262-1271.

18. Afshin A, Micha R, Khatibzadeh S, et al. (2014) Consumption of nuts and legumes and risk of incident ischemic heart disease, stroke, and diabetes: a systematic review and metaanalysis. Am J Clin Nutr 100, 278-288.

19. Luo C, Zhang Y, Ding Y, et al. (2014) Nut consumption and risk of type 2 diabetes, cardiovascular disease, and all-cause mortality: a systematic review and meta-analysis. Am J Clinc Nutr 100, 256-269.

20. Zhou D, Yu H, He F, et al. (2014) Nut consumption in relation to cardiovascular risk and type 2 diabetes: a systematic review and meta-analysis of prospective studies. Am J Clin Nutr 100, 270-277.

21. Luu HN, Blot WJ, Xiang Y-B, et al. (2015) Prospective evaluation of the association of nut/peanut consumption with total and cause-specific mortality. JAMA Intern Med 175, 755-766.

22. van den Brandt PA \& Schouten LJ (2015) Relationship of tree nut, peanut and peanut butter intake with total and causespecific mortality: a cohort study and meta-analysis. Int $J$ Epidemiol, 1-12.

23. di Giuseppe R, Fjeld MK, Dierkes J, et al. (2015) The association between nut consumption and the risk of total and ischemic stroke in a German cohort study. Eur J Clin Nutr 69, 431-435.
24. Stroup DF, Berlin JA, Morton SC, et al. (2000) Meta-analysis of observational studies in epidemiology: a proposal for reporting. Meta-analysis of Observational Studies in Epidemiology (MOOSE) group. JAMA 283, 2008-2012.

25. Wells GA, Shea B, Connell DO, et al. (2000) The NewcastleOttawa Scale (NOS) for assessing the quality of nonrandomised studies in meta-analyses. http://www.medicine.mcgill. $\mathrm{ca} / \mathrm{rtamblyn} /$ Readings/The Newcastle-Scale for assessing the quality of nonrandomised studies in meta-analyses.pdf (accessed May 2013).

26. Guyatt GH, Oxman AD, Schünemann HJ, et al. (2011) GRADE guidelines: a new series of articles in the Journal of Clinical Epidemiology. J Clin Epidemiol 64, 380-382.

27. Guyatt GH, Oxman AD, Vist GE, et al. (2008) GRADE: an emerging consensus on rating quality of evidence and strength of recommendations. BMJ 336, 924-926.

28. Guyatt G, Oxman AD, Akl EA, et al. (2011) GRADE guidelines: 1. Introduction-GRADE evidence profiles and summary of findings tables. J Clin Epidemiol 64, 383-394.

29. Robays J \& Vlayen J (2012) Dealing with fragility: optimal information size. In KCE Process B. Brussels: Belgian Health Care Knowledge Centre. http://processbook.kce.fgov.be/node/ 140 (accessed September 2015).

30. Guyatt GH, Oxman AD, Kunz R, et al. (2011) GRADE guidelines 6. Rating the quality of evidence Imprecision. J Clin Epidemiol 64, 1283-1293.

31. DerSimonian R \& Laird N (1986) Meta-analysis in clinical trials. Control Clin Trials 7, 177-188.

32. Greenland S \& Longnecker MP (1992) Methods for trend estimation from summarized dose-response data, with applications to meta-analysis. Am J Epidemiol 135, 1301-1309.

33. Orsini N, Bellocco R \& Greeland S (2006) Multivariate random-effects meta-analysis. Stata J 6, 40-57.

34. United States Department of Agriculture \& United States Department of Health and Human Services (2010) Dietary Guidelines for Americans 2010, 7th ed. Washington, DC: US Government Printing Office.

35. Egger M, Davey Smith G, Schneider M, et al. (1997) Bias in meta-analysis detected by a simple, graphical test. BMJ $\mathbf{3 1 5}$, 629-634.

36. Begg CB \& Mazumdar M (1994) Operating characteristics of a rank correlation test for publication bias. Biometrics $\mathbf{5 0}$, 1088-1101.

37. Duval S \& Tweedie R (2000) Trim and fill: a simple funnelplot-based method of testing and adjusting for publication bias in meta-analysis. Biometrics 56, 455-463.

38. The Nordic Cochrane Centre - The Cochrane Collaboration (2012) Review Manager. Copenhagen: The Nordic Cochrane Centre - The Cochrane Collaboration.

39. StataCorp LP (2015) Stata Statistical Software: Release 14. College Station, TX: StataCorp LP.

40. Bao Y, Han J, Hu FB, et al. (2013) Association of nut consumption with total and cause-specific mortality. $N$ Engl J Med 369, 2001-2011.

41. Li TY, Brennan AM, Wedick NM, et al. (2009) Regular consumption of nuts is associated with a lower risk of cardiovascular disease in women with type 2 diabetes. $J$ Nutr 139, 1333-1338.

42. Bernstein AM, Sun Q, Hu FB, et al. (2010) Major dietary protein sources and risk of coronary heart disease in women. Circulation 122, 876-883.

43. Hu FB, Stampfer MJ, Manson JE, et al. (1998) Frequent nut consumption and risk of coronary heart disease in women: prospective cohort study. BMJ 317, 1341-1345.

44. Djoussé L, Gaziano JM, Kase CS, et al. (2010) Nut consumption and risk of stroke in US male physicians. Clin Nutr 29, 605-609. 
45. Fraser GE, Sumbureru D, Pribis P, et al. (1997) Association among health habits, risk factors, and all-cause mortality in a black California population. Epidemiology 8, 168-174.

46. Fraser GE \& Shavlik DJ (1997) Risk factors for all-cause and coronary heart disease mortality in the oldest-old. Arch Intern Med 157, 2249-2258.

47. Blomhoff R, Carlsen MH, Andersen LF, et al. (2007) Health benefits of nuts: potential role of antioxidants. Br J Nutr 96, S52-S60.

48. Levitan EB, Lewis CE, Tinker LF, et al. (2013) Mediterranean and DASH diet scores and mortality in women with heart failure: the Women's Health Initiative. Circ Heart Fail 6, 1116-1123.

49. Yaemsiri S, Sen S, Tinker L, et al. (2012) Trans fat, aspirin, and ischemic stroke in postmenopausal women. Ann Neurol $\mathbf{7 2}$, 704-715.

50. Haring B, Gronroos N, Nettleton JA, et al. (2014) Dietary protein intake and coronary heart disease in a large community based cohort: results from the Atherosclerosis Risk in Communities (ARIC) Study. PLOS ONE 9, e109552.

51. Guasch-Ferré M, Bulló M, Martínez-González M, et al. (2013) Frequency of nut consumption and mortality risk in the PREDIMED nutrition intervention trial. BMC Med 11, 164.

52. Fernández-Montero A, Bes-Rastrollo M, Barrio-López MT, et al. (2014) Nut consumption and 5-y all-cause mortality in a Mediterranean cohort: the SUN project. Nutrition 30, 1022-1027.

53. van den Brandt PA (2011) The impact of a Mediterranean diet and healthy lifestyle on premature. Am J Clin Nutr 94, 913-920.

54. Mann JI, Appleby PN, Key TJ, et al. (1997) Dietary determinants of ischaemic heart disease in health conscious individuals. Heart 78, 450-455.

55. Fraser GE, LIndsted KD \& Beeson LW (1995) Effect of risk factor values on lifetime risk of and age at first coronary event. Am J Epidemiol 142, 746-758.

56. Sterne JA, Gavaghan D \& Egger M (2000) Publication and related bias in meta-analysis: power of statistical tests and prevalence in the literature. J Clin Epidemiol 53, 1119-1129.

57. Lotfi MH, Kannan AT, Dwivedi S, et al. (2008) Original report the role of adverse lifestyle changes in the causation of coronary artery disease. Acta Med Iran 46, 125-132.

58. World Health Organization \& Food and Agriculture Organization of the United Nations (2003) Diet, Nutrition and the Prevention of Chronic Diseases: Report of a Joint WHO/FAO Expert Consultation. Geneva: WHO \& FAO.

59. Lichtenstein AH, Appel LJ, Brands M, et al. (2006) Diet and lifestyle recommendations revision 2006: a scientific statement from the American Heart Association Nutrition Committee. Circulation 114, 82-96.

60. Health Canada (2012) Eating well with Canada's food guide. http://www.hc-sc.gc.ca/fn-an/alt_formats/hpfb-dgpsa/pdf/foodguide-aliment/view_eatwell_vue_bienmang-eng.pdf (accessed May 2013).

61. US Department of Agriculture \& US Department of Health and Human Services (2010) Dietary Guidelines for Americans. Washingon, DC.

62. Molyneux RJ, Mahoney N, Kim JH, et al. (2007) Mycotoxins in edible tree nuts. Int J Food Microbiol 119, 72-78.
63. Trichopoulos A, Costacou T, Bamia C, et al. (2003) Adherence to a Mediterranean diet and survival in a Greek population. N Engl J Med 348, 2599-2608.

64. Dilis V, Katsoulis M, Lagiou P, et al. (2012) Mediterranean diet and CHD: the Greek European Prospective Investigation into Cancer and Nutrition cohort. Br J Nutr 108, 699-709.

65. Mitrou PN, Kipnis V, Thie ACM, et al. (2013) Mediterranean dietary pattern and prediction of all-cause mortality in a US population. Arch Intern Med 167, 2461-2468.

66. Fung TT, Rexrode KM, Mantzoros CS, et al. (2009) Mediterranean diet and incidence of and mortality from coronary heart disease and stroke in women. Circulation 119, 1093-1100.

67. Buckland G, González CA, Agudo A, et al. (2009) Adherence to the Mediterranean diet and risk of coronary heart disease in the Spanish EPIC Cohort Study. Am J Epidemiol 170, 1518-1529.

68. Estruch R, Ros E, Salas-Salvadó J, et al. (2013) Primary prevention of cardiovascular disease with a Mediterranean diet. New Engl J Med 368, 1279-1290.

69. Barzi F, Woodward M, Marfisi RM, et al. (2003) Mediterranean diet and all-causes mortality after myocardial infarction: results from the GISSI-Prevenzione trial. Eur J Clin Nutr 57, 604-611.

70. Singh RB, Dubnov G, Niaz MA, et al. (2002) Effect of an Indo-Mediterranean diet on progression of coronary artery disease in high risk patients (Indo-Mediterranean Diet Heart Study): a randomised single-blind trial. Lancet 360, 1455-1461.

71. Sabate J, Oda K \& Ros E (2014) Nut consumption and lipid levels. Arch Intern Med 170, 821-827.

72. Banel DK \& Hu FB (2009) Effects of walnut consumption on blood lipids and other cardiovascular risk factors: a meta-analysis and systematic review. Am J Clin Nutr 90, 56-63.

73. Nash SD \& Nash DT (2008) Nuts as part of a healthy cardiovascular diet. Curr Atheroscler Rep 10, 529-535.

74. Lorente-Cebrián S, Costa AGV, Navas-Carretero S, et al. (2013) Role of omega-3 fatty acids in obesity, metabolic syndrome, and cardiovascular diseases: a review of the evidence. J Physiol Biochem 69, 633-651.

75. O'Neil CE, Keast DR, Nicklas TA, et al. (2011) Nut consumption is associated with decreased health risk factors for cardiovascular disease and metabolic syndrome in U.S. adults: NHANES 1999-2004. J Am Coll Nutr 30, 502-510.

76. Oh K, Hu FB, Manson JE, et al. (2005) Dietary fat intake and risk of coronary heart disease in women: 20 years of follow-up of the Nurses' Health Study. Am J Clin Nutr 161, 672-679.

77. Pietinen P, Ascherio A, Korhonen P, et al. (1997) Intake of fatty acids and risk of coronary heart disaese in a cohort of Finnish men. Am J Epidemiol 145, 876-887.

78. Jenkins DJ, Kendall CW, Banach MS, et al. (2011) Nuts as a replacement for carbohydrates in the diabetic diet. Diabetes Care 34, 1706-1711.

79. Stamler J (2010) Diet-heart: a problematic revisit. Am J Clin Nutr 91, 497-499.

80. Scarborough P, Rayner M, van Dis I, et al. (2010) Saturated fat and heart disease. Am J Clin Nutr 92, 459-460. 